\title{
Radiation Therapy of Head and Neck Paragangliomas: Experience from Radiotherapy Department at the National Institute of Oncology in Rabat (Morocco)
}

\author{
Guy N'da1,2*, Amine Lachgar1,2, Oswald Houessou ${ }^{1,2}$, Sanae El Majjaoui1 ${ }^{1,2}$, Hanane El Kacemi ${ }^{1,2}$, \\ Tayeb Kebdani, ${ }^{1,2}$, Nourredine Benjaafar ${ }^{1,2}$
}

\author{
${ }^{1}$ Department of Radiotherapy, National Institute of Oncology in Rabat, Rabat, Morocco \\ ${ }^{2}$ Mohammed V University, Rabat, Morocco \\ Email: *ndaguy2008@yahoo.fr
}

How to cite this paper: N'da, G., Lachgar, A., Houessou, O., El Majjaoui, S., El Kacemi, H., Kebdani, T. and Benjaafar, N. (2021) Radiation Therapy of Head and Neck Paragangliomas: Experience from Radiotherapy Department at the National Institute of Oncology in Rabat (Morocco). Journal of Cancer Therapy, 12, 268-278. https://doi.org/10.4236/jct.2021.125025

Received: April 19, 2021

Accepted: May 24, 2021

Published: May 27, 2021

Copyright $\odot 2021$ by author(s) and Scientific Research Publishing Inc. This work is licensed under the Creative Commons Attribution International License (CC BY 4.0)

http://creativecommons.org/licenses/by/4.0/

\begin{abstract}
Background and Purpose: Paragangliomas are rare tumors of the head and neck. Their management remains problematic and varies considerably depending on the center. This study reported 14 years of experience in the management of head and neck paraganglioma (HNPGls). We aimed to assess the therapeutic results of these tumors in terms of local control and overall survival. Materials and Methods: We included 16 patients followed for HNPGls and treated by radiotherapy from January 2006 to June 2018 in the National Institute of Oncology in Rabat. Results: The median age was 44.5 years (15 67). 13 patients were female and three male with a sex ratio of 4.3. Cervical mass was the common sign (56.3\%). All patients received radiation therapy. This radiation was exclusive in $43.7 \%$ of cases or adjuvant to partial surgical resection in $56.3 \%$. The median dose of radiotherapy was $54 \mathrm{~Gy}(46-60)$ and it was delivered by a three-dimensional conformal radiotherapy technique in 15 patients and volumetric modulated arc therapy in one. There were few acute complications such as grade I and II mucositis and dermatitis. After a median follow-up of 5.6 years $(2$ - 13.4), local control, defined by radiological stability or regression, was obtained in 14 patients, two patients progressed and one died. Progression-free survival rates at 5 and 7 years were $93.8 \%$ and $78.1 \%$ respectively, and overall survival at 5 and 7 years was $92.3 \%$. Conclusions: Surgery is the first-line treatment for HNPGls. When surgery is not possible or incomplete, radiotherapy has its place in the therapeutic strategy of this rare disease for long-term local control.
\end{abstract}




\section{Keywords}

Paraganglioma, Head and Neck, Radiotherapy

\section{Introduction}

Paragangliomas or chemodectomas are rare tumors arising from the paraganglia (neuroendocrine cells) located along the vascular and nerve axes of the head, neck, and spine. They are usually benign tumors that grow slowly, causing symptoms by compressing adjacent structures [1].

With an incidence of 1 in 30,000 to 100,000, head and neck paragangliomas (HNPGls) occur, in decreasing order of frequency, in the carotid body (carotid body paragangliomas), jugular bulb, the vagus nerve (CN X), and the tympanic branch of the glossopharynx (CN IX) or cervical sympathetic chain [2].

Management for HNPGls includes observation, surgery, external beam radiation therapy (EBRT), or stereotactic radiation therapy (SRT).

The primary and definitive treatment is surgical complete resection. Radiotherapy is indicated as an adjuvant treatment to partial resection or as exclusive treatment in the case of unresectable tumors or inoperable patients [3].

To the best of our knowledge, publications of cases reports of PGls treated with RT with an excellent local control exist in the literature. However, few series of cases have been reported in our practice setting [4] [5].

The present study reports therapeutic results of 14 years of experience in the management of head and neck paragangliomas in our institute.

The main objective was to determine survival rates and the secondary, to assess diagnostic, therapeutic and evolutive aspects.

\section{Materials and Methods}

This was a retrospective study of 16 patients treated for HNPGls in the radiotherapy department of the National Institute of Oncology in Rabat between January 2006 and June 2018.

We extracted data from patients' medical records stored in the Excel database of the Institute's epidemiology unit.

Eligible patients had a histologically confirmed paraganglioma or, a strong clinical and imaging suspicion of paraganglioma in the absence of surgery.

17 cases were identified, and 16 patients who received radiotherapy were included in our study. The non-included case was determined after complete surgical removal.

Subsequently, we collected data on patient demographics, tumor characteristics, clinical, paraclinical signs, symptoms, treatments received, and follow-up.

We used SPSS v 20 for data entry and statistical analysis.

Local control and survival rates were estimated using the Kaplan-Meier method. The log-rank test and the Cox proportional hazards regression model were 
used in the comparison of survival curves. The significance level was $5 \%$ or less.

\section{Results}

The median age was 44.5 years $(15-67)$.

13 patients were female and 3 males with a sex ratio of 4.3 .

Cervical mass was the common sign (56.3\%).

Almost one-third of patients had cranial nerve damage.

The location of the PGl was jugular (6 cases); carotid (5 cases); jugular-tympanic ( 4 cases) and temporal ( 1 case).

The size of the tumours ranged from 1.6 to $6.9 \mathrm{~cm}$.

There was histological confirmation in $50 \%$ of the cases.

9 patients (56.3\%) were class $\mathrm{C}$ according to the FISCH staging system (Table 1).

9 patients received surgery.

All patients received radiation therapy, which was adjuvant for incomplete surgery in $56.3 \%$ of cases. The median dose of radiotherapy was 54 Gy (46 - 60). The technic used as three-dimensional conformal radiotherapy in 15 patients and modulated volumetric therapy in one.

No patients were treated with stereotactic radiotherapy.

Symptoms improvement in 12 patients.

Table 1. Patient and tumor characteristics.

\begin{tabular}{|c|c|c|}
\hline \multicolumn{2}{|c|}{ Characteristics } & $\mathrm{N}=16$ \\
\hline \multicolumn{2}{|c|}{ Age $^{*}$} & $44.5(15-67)$ \\
\hline \multirow{2}{*}{ Gender } & male & $3(18.3)$ \\
\hline & female & $13(81.7)$ \\
\hline \multicolumn{2}{|c|}{ Development time* } & $2.5(1-5)$ \\
\hline \multirow{4}{*}{ Sign } & cervical mass & $9(56.3)$ \\
\hline & tinnitus & $3(18.8)$ \\
\hline & otalgia & $3(18.8)$ \\
\hline & vertigo & $1(6.3)$ \\
\hline \multicolumn{2}{|c|}{ Cranial nerve damage } & $5(31.2)$ \\
\hline \multirow{4}{*}{ Location of the PG } & jugular & $6(37.5)$ \\
\hline & carotid & $5(31.3)$ \\
\hline & jugulo-tympanum & $4(25)$ \\
\hline & temporal & $1(6.3)$ \\
\hline \multicolumn{2}{|c|}{ Maximum size of tumor ${ }^{* *}$. } & $4(1.6-6.9)$ \\
\hline \multicolumn{2}{|c|}{ Pathological confirmation } & $8(50)$ \\
\hline \multirow{2}{*}{ FISCH class } & class $\mathrm{C}$ & $9(56.3)$ \\
\hline & class D & $7(42.7)$ \\
\hline
\end{tabular}

${ }^{\star}$ Median (year); ${ }^{*}$ Median (centimeter), tumor size available in 14 patients. 
Acute complications were grade I-II mucositis in four patients and grade I dermatitis in two patients.

After a median follow-up of 5.6 years $(2-13.4) .14$ patients achieved local control, defined as either stability or radiological regression. Two patients progressed and one died of lymph node, mediastinal, and lung metastasis 4 years after radiotherapy.

Progression-free survival (PFS) rates at 5 and 7 years were $93.8 \%$ and $78.1 \%$ respectively and overall survival (OS) rate at 5 and 7 years was $92.3 \%$ (Figures 1-4).

In multivariate analysis, age, gender, FISH class, treatment modalities and radiotherapy dose were not associated with PFS or OS (Table 2).

Table 2. Multivariate analysis of factors for progression-free survival and overall survival.

\begin{tabular}{ccccc}
\hline \multirow{2}{*}{ variable } & \multicolumn{3}{c}{ PFS } & \multicolumn{2}{c}{ OS } \\
\cline { 2 - 5 } & p value & HR $(95 \%$ CI $)$ & p value & HR (95\% CI) \\
\hline Age & 0.23 & $0.39(0.08-1.83)$ & 0.76 & $0.74(0.10-5.21)$ \\
Male vs Female & 0.85 & $0.01(0.00-1770)$ & 0.95 & $0.02(0.00-6158)$ \\
Class C vs Class D* & 0.24 & $0.00(0.00-1412)$ & 0.96 & $0.19(0.00-6158)$ \\
Surgery + RT vs RT & 0.24 & $0.00(0.00-1185)$ & 0.96 & $0.04(0.00-1764)$ \\
RT dose $\geq 5$ 54 Gy vs <54 Gy & 0.27 & $0.00(0.00-1170)$ & 0.98 & $0.34(0.00-6094)$ \\
\hline
\end{tabular}

$\mathrm{PFS}=$ progression -free survival, $\mathrm{OS}=$ overall survival, $\mathrm{HR}=$ Hazard Ratio, $95 \% \mathrm{CI}=95 \%$ confidence in terval; RT $=$ Radiation therapy; ${ }^{\star}$ FISCH stage.

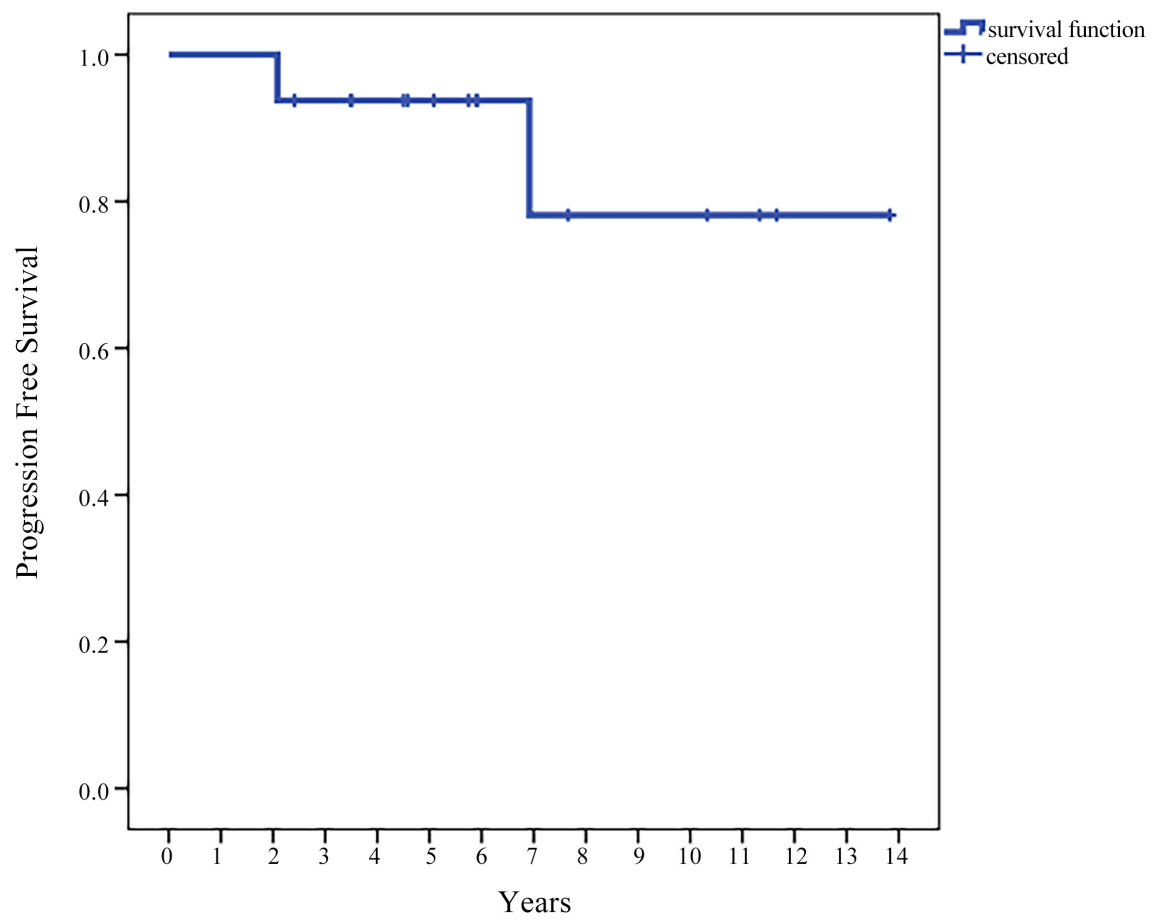

Figure 1. Kaplan-Meier estimates of PFS of head and neck paragangliomas treated with radiotherapy. 


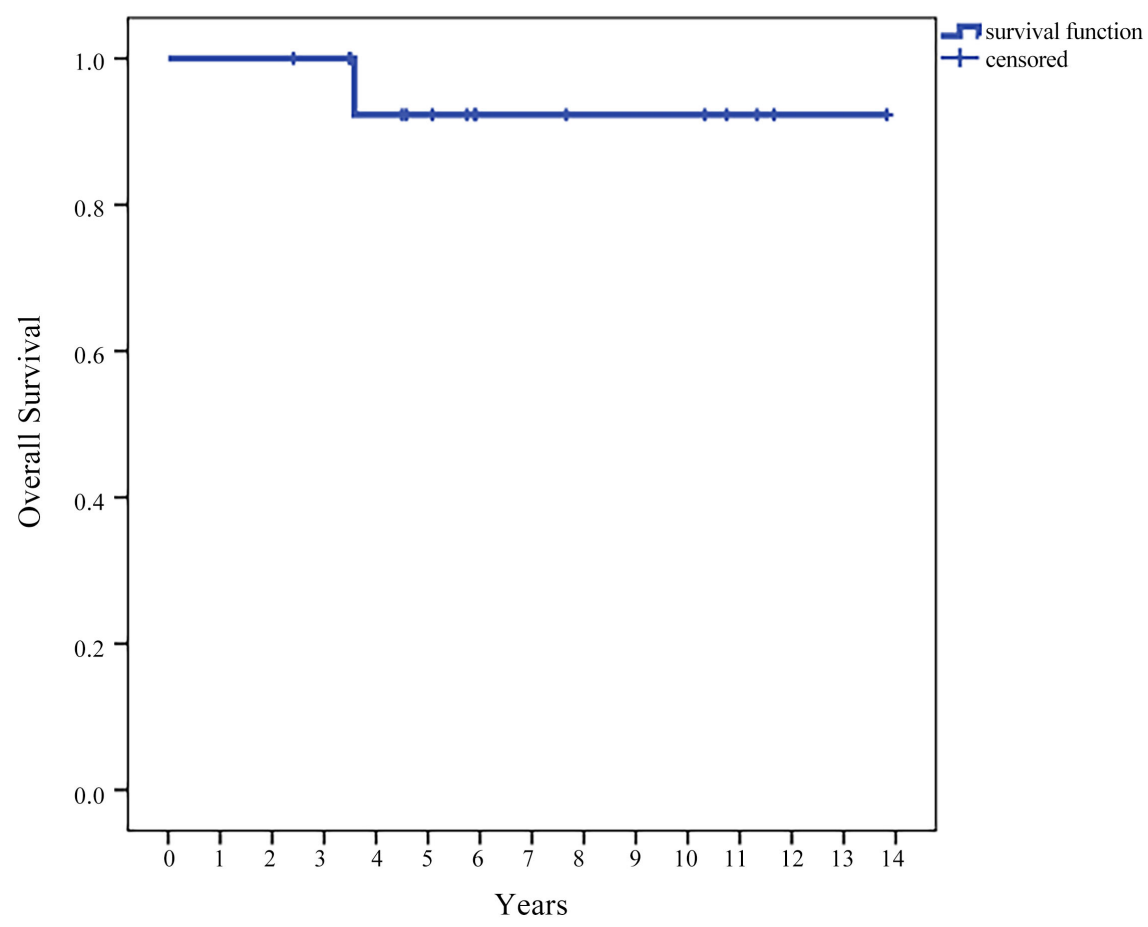

Figure 2. Kaplan-Meier estimates of OS for head and neck paragangliomas treated with radiotherapy.



Figure 3. MRI T1 sequence with an injection of gadolinium, showing on an axial slice the aspect of a PG extended to the right jugular foramen (tumour surrounded by the red line) in a 59-year-old patient followed at the National Institute of Oncology in Rabat. 


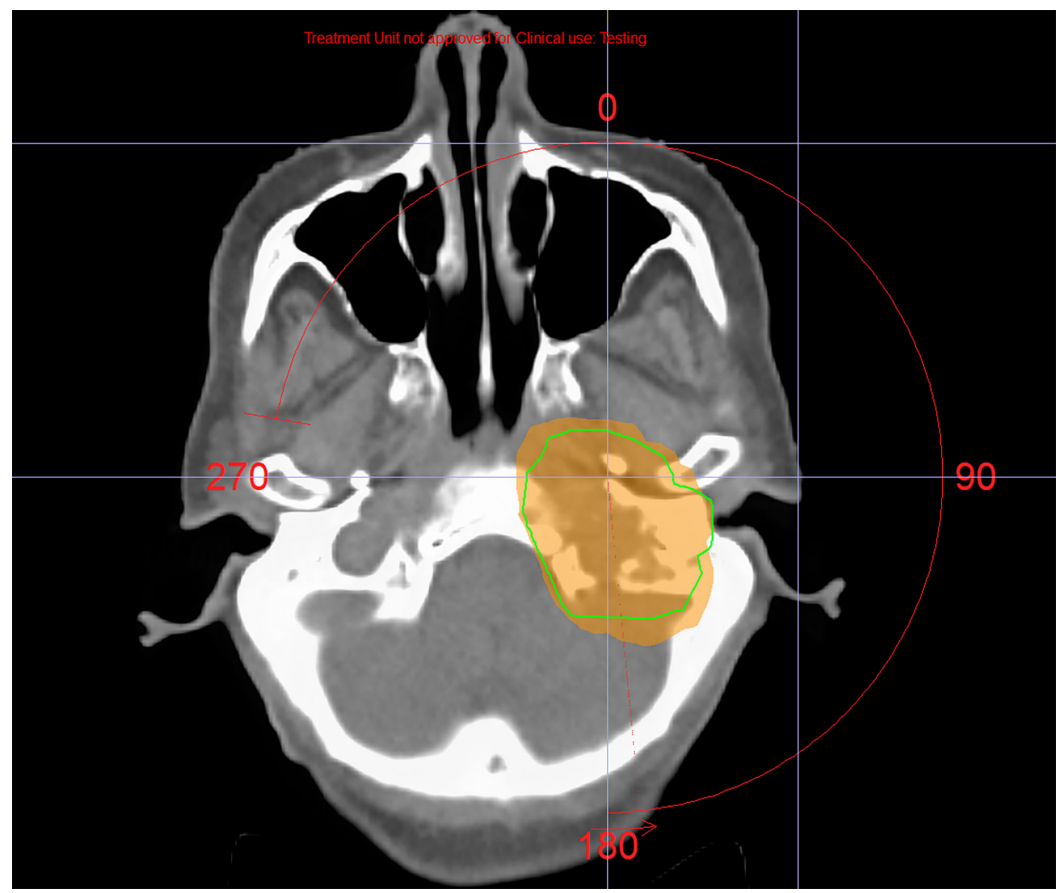

Figure 4. Axial view of the treatment plan of the same patient in Modulated Volumetric Arc Therapy (VMAT). PTV (Planning Target Volume) 60 Gy (green line); isodose $57 \mathrm{~Gy}(95 \%)$ in orange.

\section{Discussion}

We report 14 years of experience in a single center during which 16 patients were treated for HNPGls. The median age of 44.5 years at the time of diagnosis was lower than the median age of 50 years found in the literature. In addition, the maximum and minimum age was extended in most of the publications found. Thus, according to Kollert et al., the median age was 49 years (26 - 75) and Papaspyrou 52 years (10 - 85) [6] [7]. However, PGls rarely affect children [8].

The female predominance observed in our series was also observed in various studies, with a sex ratio ranging from 1.7 to 10 . According to these publications, the distribution by sex is related to the location of the tumour. Thus, carotid paragangliomas often affect males, whereas jugular, temporal and vagal paragangliomas are found in women [9] [10] [11].

Paragangliomas are rare tumors often found in the head and neck. They represent $0.6 \%$ of all tumours in this region and $3 \%$ of all paragangliomas, including pheochromocytomas [12] [13].

In our series, the tumours were located in the jugular glomus in $37 \%$ of cases and the carotid artery in $31 \%$. This distribution is in line with the literature with $18 \%-36 \%$ of PG H\&N in the jugular and tympanic veins. However, in contrast to our results, $60 \%-80 \%$ of paragangliomas were in the carotid and $3 \%-4 \%$ vagal [14].

The Fisch and Mattox classification was frequently used for HNPGls. It divides glomus tumors into four classes according to the extent of the tumor, the destruction of the cortical part of the jugular bulb, and the intracranial extension 
[15].

$56.3 \%$ of patients in the present study were class $\mathrm{C}$ according to Fisch and Mattox classification system. Also, the PFS $(p=0.424)$ and OS $(p=0.954)$ were not statistically different between FISCH class $\mathrm{C}$ and $\mathrm{D}$. Indeed, all patients with class $\mathrm{D}$ tumors had a $\mathrm{C}$ compartment. Both class $\mathrm{C}$ and $\mathrm{D}$ are advanced tumours with similar tumor patterns.

Management of paragangliomas varies considerably depending on the center. Observation, surgery, radiotherapy, and stereotactic radiation may be instituted alone or in combination. Treatment depends on the size, extent of the tumor, initial treatment, age, overall state, and neurological status of the patient [16].

Surgery is the only therapeutic option that offers immediate and complete removal of PGls. Surgery aims to have a total resection, but due to their vascularity and the involvement of critical vascular and neural structures, the total removal of these lesions may be responsible for significant morbidity risks [17]. Thus, surgery is recommended for young patients with a relatively small tumour that can be completely resected with minimal morbidity. Surgical resection of larger lesions, particularly those extending to the base of the skull (FISCH class $\mathrm{C}$ or D), may require the resection of cranial nerves. Therefore, they are better treated with radiotherapy.

Nine patients $(56.3 \%)$ of the 16 in our series underwent partial surgical resection before adjuvant salvage radiotherapy. Subtotal resection followed by adjuvant radiotherapy had no significant impact on PFS $(\mathrm{p}=0.523)$. This observation was also stated by Chino et al. with non-significant local control ( $\mathrm{p}=0.31)$ [6]. Hinerman and al. concluded that there was no benefit to subtotal surgical resection [18]. Even more, according to a publication by Gstoettner and al., primary radiotherapy seems to have better results than postoperative radiation after incomplete tumour resection [10].

In the absence of an indication for surgery, EBRT or SRT can be an effective and safe alternative for the treatment of PGls. Indeed, radiotherapy has been used for the last decades as exclusive, combined, or salvage treatment in unresectable tumours or in patients who are not operable due to advanced age or comorbidities [3].

All 16 patients in our series received external beam radiation therapy (exclusive or adjuvant). 3D conformal radiotherapy (RTC 3D) was used in 15 patients and modulated volumetric therapy (VMAT) in one. The overall tolerance was good.

Commonly used radiation doses range from 32 to $60 \mathrm{~Gy}$ in 16 to 30 fractions [3]. Kim et al. examined 200 patients treated with exclusive or adjuvant radiotherapy for residual tumor after surgery and found a $2 \%$ local recurrence rate in patients who received total doses greater than $40 \mathrm{~Gy}$ in 4 weeks compared with $22 \%$ in those who received less than $40 \mathrm{~Gy}$ [19]. In addition, Mumber and Greven found no local recurrence among 15 patients treated with exclusive or adjuvant radiotherapy with prescribed doses of $45-60$ Gy in $1.43-2$ Gy/fraction [20]. 
In our series, the median dose of radiotherapy was $54 \mathrm{~Gy}(46$ - 60), and there was no benefit in local control at 5 years for doses higher than this median dose $(\mathrm{p}=0.95)$.

Chino and al. also found no significant difference for doses above 54 Gy (10-year CL: $91 \%$ for $<54$ Gy versus $88 \%>54 \mathrm{~Gy}, \mathrm{p}=0.71$ ) [6].

Thus, Zabel and col recommend 57.6 to $60 \mathrm{~Gy}$ in 1.8 to $2 \mathrm{~Gy}$ per fraction as the optimal dose with conformal techniques [11].

Some authors have analyzed the benefit of using 3D conformal radiotherapy with or without intensity modulation (IMRT) compared to conventional twodimensional radiotherapy. There was a non-significant trend $(\mathrm{p}=0.28)$ towards better outcomes with conformal approaches. However, IMRT has the particularity of improving the homogeneity of the dose within the target while sparing the surrounding normal tissue. Consequently, the use of IMRT in the treatment of PGls results in better tolerability compared to conventional two-dimensional or three-dimensional conformal radiotherapy, though strict dosimetric comparisons of dose-volume histograms generated with IMRT and other approaches have not been described [6].

For more than a decade, stereotactic radiotherapy has proven to be a safe and effective form of treatment. It is suitable for the treatment of PGs of the base of the skull base of up to $3 \mathrm{~cm}$ [21]. The advantage of using SRT is the highly conformal single fraction delivery of 12 - 20 Gy to the target. Early series using this technic have reported $75 \%$ - 100\% local control, with minimal effects on normal tissue [22] [23] [24] [25] [26]. Three patients in our series with a tumor less than $3 \mathrm{~cm}$ could have benefited from SRT, but no indication for SRT was given, mainly because our institution just recently acquired this technology.

PGls are relatively radiosensitive tumors; however, complete remission with radiotherapy is rare. In general, with radiotherapy, long-term tumor stabilization or partial regression is the objective [27] [28]. Thus, after a median follow-up of 5.6 years, local control was observed in 14 of our patients, with PFS at 5 and 7 years of $93.8 \%$ and $78.1 \%$ respectively. The OS at 5 and 7 years was estimated at $92.3 \%$.

Several retrospective series with local control and overall survival rates comparable to ours have been published:

Indeed, Gilbo et al. reported irradiation experience of 131 patients over 45 years, with mean and median follow-up times of 11.5 years and 8.7 years, local control rates at 5 and 10 years of $99 \%$ and $96 \%$, and overall survival rates at 5 and 10 years of $91 \%$ and $72 \%$ respectively [27]. Zabel et al. also found, after a median follow-up of 5.7 years (1.6 - 14.7), a crude local tumor control rate of $91 \%$ (20 of 22 patients) and an actuarial local tumor control rate of $90.4 \%$ at 5 and 10 years. The overall survival rate was $89.5 \%$ at 5 and 10 years [11]. Similarly, the 10-year tumor control rate reported by Krych et al. in their series of 33 patients (25 treated with RT and 8 with SRT) was 92\% (75\% - 98\%), with a longer median follow-up of 13 years, and no patient developed a radiation-induced malignancy [16]. 
The limitations in our study are related to the small number of patients due to the rarity of paragangliomas and the short duration of follow-up, which does not allow identification of all the late toxicities of radiotherapy.

Despite these limitations, the present study, as several other publications shows that RT and SRT provide excellent long-term control of PGs while causing few treatment-related complications.

These therapies, therefore, have an important role in the treatment strategy for these tumors.

\section{Conclusions}

Paragangliomas are rare tumors of the head and neck. They are slow-growing and can spread to the vascular and bony structures of the base of the skull.

Complete surgical resection remains the first-line treatment.

Exclusive or salvage radiotherapy is the only treatment option.

Our study has led us to find that:

Radiotherapy in the treatment of head and neck paragangliomas provides clinical benefit, excellent local control, and good tolerance.

In addition, our data suggest no benefit for subtotal surgical resection before radiotherapy in the management of these tumors.

Long-term follow-up with a larger sample size is necessary to support the local control and long-term overall survival benefit of radiation therapy in HNPGls.

More accurate radiotherapy techniques such as stereotactic radiotherapy or intensity-modulated radiation therapy are becoming the standard in the management of this rare disease.

\section{Contributions from the Authors}

Guy N'da collected the data and wrote the article, Amine Lachgar and Oswald Houessou participated in the proofreading of the article, Sanaa El Majjaoui, Hanan El Kacemi, Tayeb Kebdani and Noureddine Benjaafar participated in the revising critically of the content and gave final approval of the version to be published.

\section{Conflicts of Interest}

The authors declare no conflicts of interest regarding the publication of this paper.

\section{References}

[1] Martin, T.P., Irving, R.M. and Maher, E.R. (2007) The Genetics of Paragangliomas: A Review. Clinical Otolaryngology, 32, 7-11. https://doi.org/10.1111/j.1365-2273.2007.01378.x

[2] Pellitteri, P.K., Rinaldo, A., Myssiorec, D., et al. (2004) Paragangliomas of the Head and Neck. Oral Oncology, 40, 563-575. https://doi.org/10.1016/j.oraloncology.2003.09.004

[3] Larner, J.M., Hahn, S.S., Spaulding, C.A. and Constable, W.C. (1992) Glomus Jugu- 
lare Tumors. Long Term Control by Radiation Therapy. Cancer, 69, 1813-1817. https://doi.org/10.1002/1097-0142(19920401)69:7<1813::AID-CNCR2820690725>3. $\underline{0 . \mathrm{CO} ; 2-\mathrm{P}}$

[4] Lalya, I., Mechchat, A., Lalyac, I., Kebdani, T., Hassounia, K., Kanouni, L., et al. (2011) Efficacité de la radiothérapie en première intention d'un paragangliome carotidien non résécable. Journal des Maladies Vasculaires, 36, 185-188. https://doi.org/10.1016/j.jmv.2010.12.002

[5] Ma, Z., Parsai, S., Gandhidasan, S. and Suh, J.H. (2017) Paraganglioma of the Skull Base Treated with Intensity-Modulated Radiation Therapy. Applied Radiation Oncology, March, 30-32. http://www.appliedradiationoncology.com

[6] Chino, J.P., Sampson, J.H., Tucci, D.L., Brizel, D.M. and Kirkpatrick, J.P. (2009) Paraganglioma of the Head and Neck: Long-Term Local Control with Radiotherapy. American Journal of Clinical Oncology, 32, 304-307. https://doi.org/10.1097/COC.0b013e318187dd94

[7] Kollert, M., Minovi, A.A., Draf, W. and Bockmuhl, U. (2006) Cervical Paragangliomas-Tumor Control and Long-Term Functional Results after Surgery. Skull Base, 16, 185-191. https://doi.org/10.1055/s-2006-950386

[8] Papaspyrou, K., Mann, W.J. and Amedee, R.G. (2009) Management of Head and Neck Paragangliomas: Review of 120 Patients. Head Neck, 31, 381-387. https://doi.org/10.1002/hed.20967

[9] Smith, J.D., Harvey, R.N., Darr, O.A., Prince, M.E., Bradford, C.R., Wolf, G.T., et al. (2017) Head and Neck Paragangliomas: A Two-Decade Institutional Experience and Algorithm for Management Laryngoscope. Laryngoscope Investigative Otolaryngology, 2, 380-389. https://doi.org/10.1002/lio2.122

[10] Gstoettner, W., Matula, C., Hamzavi, J., Kornfehl, J. and Czerny, C. (1999) LongTerm Results of Different Treatment Modalities in 37 Patients with Glomus Jugulare Tumors. European Archives of Oto-Rhino-Laryngology, 256, 351-355. https://doi.org/10.1007/s004050050162

[11] Zabel, A., Milker-Zabel, S., Huber, P., et al. (2004) Fractionated Stereotactic Conformal Radiotherapy in the Management of Large Chemodectomas of the Skull Base. International Journal of Radiation Oncology, Biology, Physics, 58, 1445-1450. https://doi.org/10.1016/j.ijrobp.2003.09.070

[12] Borba, L.A. and Al-Mefty, O. (1996) Intravagal Paragangliomas: Report of Four Cases. Neurosurgery, 38, 569-575. https://doi.org/10.1227/00006123-199603000-00030

[13] Lack, E. (1997) Tumors of the Adrenal Gland and Extra-Adrenal Paragangliomas. In: Atlas of Tumor Pathology, Series 3, FASC 19, Armed Forces Institute of Pathology, Washington DC. https://books.google.com

[14] Van Baars, F.M., Cremers, C.W., van den Broek, P., et al. (1981) Familiar NonChromaffinic Paragangliomas (Glomus Tumors). Clinical and Genetic Aspects (Abridged). Acta Oto-Laryngologica, 91, 589-593. https://doi.org/10.3109/00016488109138545

[15] Fisch, U. and Mattox, D. (1988) Microsurgery of the Skull Base. Thieme, New York.

[16] Krych, A.J., Foote, R.L., Brown, P.D., et al. (2006) Long-Term Results of Irradiation for Paraganglioma. International Journal of Radiation Oncology, Biology, Physics, 65, 1063-1066. https://doi.org/10.1016/j.ijrobp.2006.02.020

[17] Suarez, C., Rodrigo, J.P., Bodeker, C.C., Llorente, J.L., Silver, C.E., Jansen, J.C., et al. (2012) Jugular and Vagal Paragangliomas: Systematic Study of Management with Surgery and Radiotherapy. Head \& Neck, 35, 1195-1204. 
https://doi.org/10.1002/hed.22976

[18] Hinerman, R.W., Mendenhall, W.M., Amdur, R.J., et al. (2001) Definitive Radiotherapy in the Management of Chemodectomas Arising in the Temporal Bone, Carotid Body, and Glomus Vagale. Head Neck, 23, 363-371.

https://doi.org/10.1002/hed.1045

[19] Kim, J.A., Elkon, D., Lim, M.L., et al. (1980) Optimum Dose of Radiotherapy for Chemodectomas of the Middle Ear. International Journal of Radiation Oncology, Biology, Physics, 6, 815-819. https://doi.org/10.1016/0360-3016(80)90317-X

[20] Mumber, M.P. and Greven, K.M. (1995) Control of Advanced Chemodectomas of the Head and Neck with Irradiation. American Journal of Clinical Oncology, 18, 389-391. https://doi.org/10.1097/00000421-199510000-00005

[21] Maarouf, M., Voges, J., Landwehr, P., et al. (2003) Stereotactic Linear Accelerator-Based Radiosurgery for the Treatment of Patients with Glomus Jugulare Tumors. Cancer, 97, 1093-1098. https://doi.org/10.1002/cncr.11118

[22] Eustacchio, S., Leber, K., Trummer, M., et al. (1999) Gamma Knife Radiosurgery for Glomus Jugulare Tumours. Acta Neurochirurgica (Wien), 141, 811-818. https://doi.org/10.1007/s007010050381

[23] Foote, R.L., Coffey, R.J., Gorman, D.A., et al. (1997) Stereotactic Radiosurgery for Glomus Jugulare Tumors: A Preliminary Report. International Journal of Radiation Oncology, Biology, Physics, 38, 491-495. https://doi.org/10.1016/S0360-3016(97)89482-5

[24] Liscak, R., Vladyka, V., Simonova, G., et al. (1998) Leksell Gamma Knife Radiosurgery of the Tumor Glomus Jugulare and Tympanicum. Stereotactic and Functional Neurosurgery, 70, 152-160. https://doi.org/10.1159/000056417

[25] Pollock, B.E. (2004) Stereotactic Radiosurgery in Patients with Glomus Jugulare Tumors. Neurosurgical Focus, 17, E10. https://doi.org/10.3171/foc.2004.17.2.10

[26] Poznanovic, S.A., Cass, S.P. and Kavanagh, B.D. (2006) Short-Term Tumor Control and Acute Toxicity after Stereotactic Radiosurgery for Glomus Jugulare Tumors. Otolaryngology_-Head and Neck Surgery, 134, 437-442. https://doi.org/10.1016/j.otohns.2005.10.040

[27] Gilbo, P., Morris, C.G., Amdur, R.J., Werning, J.W., Dziegielewski, P.T., Kirwan, J., et al. (2014) Radiotherapy for Benign Head and Neck Paragangliomas: A 45-Year Experience. Cancer, 120, 3738-3743. https://doi.org/10.1002/cncr.28923

[28] Mendenhall, W.M., Amdur, R.J., Vaysberg, M., et al. (2011) Head and Neck Paragangliomas. Head Neck, 33, 1530-1534. https://doi.org/10.1002/hed.21524 